\title{
Article
}

\section{Dissatisfaction with Local Medical Services for Middle-Aged and Elderly in China: What Is Relevant?}

\author{
Xiaojing Fan ${ }^{1}$, Min $\mathrm{Su}^{2, *}$, Yaxin Zhao $^{3}$ and Duolao Wang ${ }^{4} \mathbb{D}$ \\ 1 School of Public Policy and Administration, Xi'an Jiaotong University, Xi'an 710049, China; \\ fanxj112@xjtu.edu.cn \\ 2 School of Public Administration, Inner Mongolia University, Hohhot 010021, China \\ 3 School of Public Health, Xi'an Jiaotong University Health Science Center, Xi'an 710061, China; \\ zhaoyaxin1996@stu.xjtu.edu.cn \\ 4 Department of Clinical Sciences, Liverpool School of Tropical Medicine, Liverpool L3 5QA, UK; \\ duolao.wang@lstmed.ac.uk \\ * Correspondence: 111989029@imu.edu.cn; Tel.: +86-131-9051-0058
}

Citation: Fan, X.; Su, M.; Zhao, Y.; Wang, D. Dissatisfaction with Local Medical Services for Middle-Aged and Elderly in China: What Is Relevant?. Int. J. Environ. Res. Public Health 2021, 18, 3931. https:// doi.org/10.3390/ijerph18083931

Received: 18 March 2021

Accepted: 7 April 2021

Published: 8 April 2021

Publisher's Note: MDPI stays neutra with regard to jurisdictional claims in published maps and institutional affiliations.

Copyright: (c) 2021 by the authors. Licensee MDPI, Basel, Switzerland. This article is an open access article distributed under the terms and conditions of the Creative Commons Attribution (CC BY) license (https:// creativecommons.org/licenses/by/ $4.0 /)$.

\begin{abstract}
As violent clashes between doctors and patients in China intensify, patient dissatisfaction has been identified as a major concern in the current healthcare reform in China. This study aims to investigate the main determinants of dissatisfaction with local medical services attributable to middle-aged and elderly characteristics and identify areas for improvement. A total of 14,263 rural participants and 4898 urban participants were drawn from the China Health and Retirement Longitudinal Study in 2018. Dissatisfaction was measured by two methods: binary outcome $(1$ = Dissatisfaction; $0=\mathrm{No})$ demonstrated the risk of occurring dissatisfaction among various characteristics, and continuous outcome (ranges from score 1 to 5) showed the degree. The mean score of dissatisfaction was $2.73 \pm 1.08$. Sixteen percent of rural participants and $19 \%$ of urban participants reported dissatisfaction with local medical services, respectively. The multilevel analyses demonstrated that participants' utilization of paid family doctor services decreased the risk of occurring dissatisfaction; dissatisfaction was less focused on females; having chronic diseases increased the risk of dissatisfaction. This study suggests promotion of family doctor services can effectively reduce middle-aged and elderly dissatisfaction with the local medical services. In addition, more attention should be focused on males and middle-aged and elderly with chronic diseases in order to decrease dissatisfaction.
\end{abstract}

Keywords: dissatisfaction; local medical services; determinants; binary outcome; middle-aged and elderly person

\section{Introduction}

The views of patients are becoming increasingly important in the process of improving the health system [1,2]. Patient dissatisfaction refers to the attitude or feeling of being unsatisfied, displeased or disappointed when using healthcare services [3]. It is a measure of the level of content of care they receive from medical institutions and is a significant performance dimension that provides healthcare managers and professionals with useful insights for improving the quality and effectiveness of care [2,4-6]. In China, despite a range of health policies to provide greater health benefits to citizens, patient dissatisfaction with medical services continues to rise and can even escalate into serious incidents of violence against doctors. Studies show that violence in healthcare facilities has increased 10 times in the last 10 years [7]. The growing tension between patients and healthcare providers has challenged China's current healthcare reforms, making patient dissatisfaction one of the primary concerns of the health system.

Based on a literature search, we found that most dissatisfaction surveys are based on quantitative cross-sectional studies $[2,5,8,9]$, cohort studies [10] or qualitative inter- 
views [11]. Several studies have investigated that patient satisfaction is shaped by some determinants including personal characteristics, preference, expectation and the quality of care received in other countries based on cross-sectional surveys [5,12-14]. In addition, a cross-sectional study in Switzerland found that the most satisfied patients were the most likely to participate in a post-hospitalization satisfaction survey [8]. In Pakistan, a low level of patient satisfaction was found to be correlated with the medical services [15]; scholars found that the development of the interpersonal and clinical skills of doctors could improve patient satisfaction [16]. A cross-sectional study in Italian university hospitals also found that lower patient satisfaction was associated with a higher patients leaving hospital against medical advice rates [2]. Studies that emerged from China recently are only limited to selected groups, tertiary public hospitals, certain types of treatments or health conditions [17]. For example, in a sample of 300 inpatients in one tertiary public hospital it was found that the discharge and admission process does not yet meet patient expectations [18]. To investigate provider-related factors, a cross-sectional study found that higher levels of trust, lower levels of hospital medical expenditure and good staff attitude were key predictors of patient satisfaction [9]. Some scholars studied the impact of both patient- and provider-related characteristics on patient satisfaction in urban China by a cohort study [10].

The previously mentioned studies provide useful insight. However, there is limited evidence from both urban and rural China focusing on the patients' dissatisfaction and to what degree patient characteristics explain dissatisfaction among middle-aged and elderly. With the rapid development of the Chinese economy, people aged 60 years and over accounted for $13.26 \%$ of the total, according to the result of the sixth national census, up 2.93 percentage points from the fifth national census, and $8.87 \%$ of people aged 65 and over, up 1.91 percentage points from the fifth national census [19]; the aging process is beginning to accelerate gradually. Studies have found that aging largely alters the functional capacity of the human body $[20,21]$ and is strongly associated with the incidence of common diseases, chronic illnesses and cancer [22-24]. With the changing age structure of the world's population and the gradual increase in aging in China, the middle-aged and elderly population will make up the majority of the groups utilizing healthcare services in the future, research on dissatisfaction among them would be an important reference for targeted efforts to improve the health care experience of the target population, promote a good health care environment and reduce social risks. All of these arguments mentioned above make our study an innovative and original piece of work.

In this study, we explored patients' dissatisfaction with local health services among middle-aged and elderly people by adopting a nationally representative cross-sectional survey data in China. The findings uncover the level of patients' dissatisfaction from the largest and most populated developing countries, investigate the relationship between patients' dissatisfactions and their characteristics (such as sociodemographic characteristics and health services utilization) in rural and urban areas and reveal the relative significant reasons for dissatisfaction. The ultimate aim is to help managers in hospitals and policymakers to take target measures for improving patient satisfaction. In the following sections, the sources of the research data, the selection of key variables and the methods of analysis, the findings and the discussion are presented separately.

\section{Methods}

\subsection{Data Sources}

Data were obtained from nationally representative face-to-face household surveys in 2018, the China Health and Retirement Longitudinal Study (CHARLS). The conceptual basis and design of the CHARLS have been described extensively in the literature [25,26]. The CHARLS utilizes a multi-stage probability proportional scale sampling method to randomly select Chinese middle-aged and elderly and their spouses from 150 counties and 450 communities/villages across 28 provinces as respondents [27]. In this study, a total of 14,263 rural participants and 4898 urban participants aged more than 45 years old 
were selected. Based on previous theoretical studies on the process of patient satisfaction formation [10,28-30], research on the determinants affecting patient dissatisfaction can help improve patient evaluations and therefore patient satisfaction. The framework for the empirical exploration of patient dissatisfaction in this paper is shown in Figure 1.

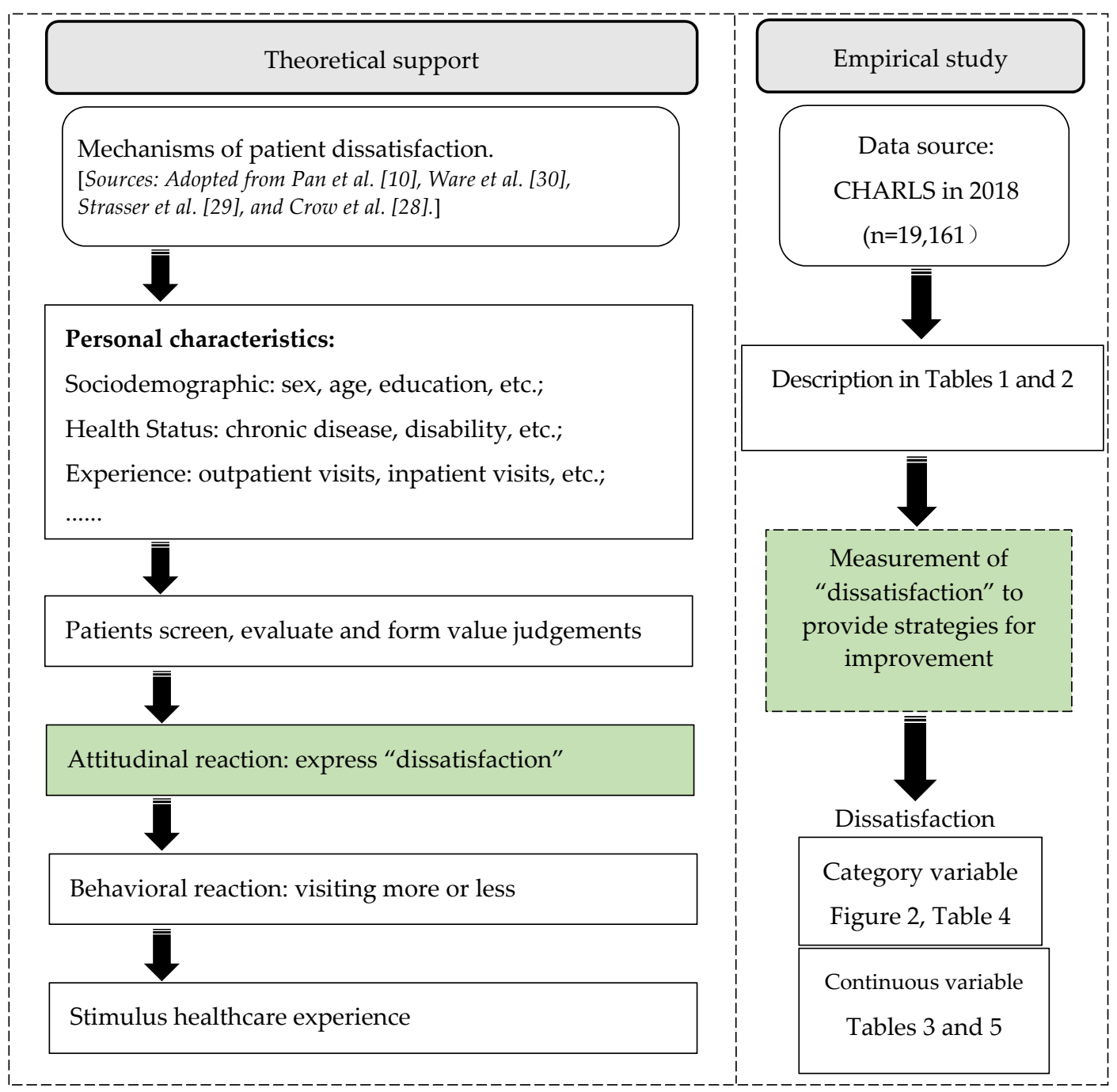

Figure 1. Flowchart of the study.

\subsection{Variables}

Individual dissatisfaction was the dependent variable, and it was based on the middleaged and elderly reports in the 2018 wave on the following item: "Are you satisfied with the quality, cost and convenience of local medical services? Choose from very satisfied (1), somewhat satisfied (2), neutral (3), somewhat dissatisfied (4) and very dissatisfied (5)". Two methods were used to analyze dissatisfaction. Firstly, we grouped dissatisfaction as a binary variable, whereby 0 denoted "no", including "very satisfied, somewhat satisfied and neutral"; 1 denoted "yes" including "somewhat dissatisfied and very dissatisfied". Secondly, we treated dissatisfaction as a continuous variable, and it was measured by the above item on a five-point Likert scale and ranged from score 1 to 5 . We assigned a score to each category: score 1 for "very satisfied", score 2 for "somewhat satisfied", score 3 for "neutral", score 4 for "somewhat dissatisfied" and score 5 for "very dissatisfied". The higher the score, the higher the level of dissatisfaction. The independent variables were sociodemographic factors (participants' sex, age, education, economic and living status and chronic diseases) and utilization of outpatient, inpatient and paid family doctor services 
based on previous studies but constrained by the variables collected in the CHARLS (Table 1) $[10,13,31,32]$.

Table 1. Values assigned to the independent variables in multilevel modeling.

\begin{tabular}{|c|c|}
\hline Variables & Description and Value \\
\hline Dissatisfaction & $\begin{array}{l}\text { Binary variable: } 0=\text { Yes (somewhat dissatisfied and very } \\
\text { dissatisfied); } 1=\text { No (very satisfied, somewhat satisfied } \\
\text { and neutral) } \\
\text { Continuous variable, ranging from score } 1 \text { to } 5\end{array}$ \\
\hline Type of residence & $0=$ Rural; $1=$ Urban \\
\hline Sex & $0=$ Male $; 1=$ Female \\
\hline Age (years) & $1=45-50 ; 2=51-60 ; 3=61-70 ; 4=\geq 71$ \\
\hline Education & $\begin{array}{l}0=\text { Illiterate } ; 1=\leq \text { Elementary school } ; 2=\geq \text { Middle } \\
\text { school }\end{array}$ \\
\hline Living status & $0=$ Live with others $; 1=$ Live alone \\
\hline Economic status & $1=$ Low $; 2=$ Middle; $3=$ High \\
\hline Chronic diseases & $0=\mathrm{No} ; 1=\mathrm{Yes}$ \\
\hline Utilizing outpatients in the last month & $0=$ No; $1=$ Yes \\
\hline Utilizing inpatients in the past year & $0=\mathrm{No} ; 1=\mathrm{Yes}$ \\
\hline Utilizing paid family doctor services & $0=\mathrm{No} ; 1=$ Yes \\
\hline
\end{tabular}

\subsection{Data Analysis}

Multilevel mixed-effect models were applied to explore the determinants for dissatisfaction with local medical services from the individual's perspective. These determinants in Table 1 were specified as the fixed effect, and the community where participants lived was a random effect. The odds ratios (ORs) with 95\% confidence limits (CLs) in multilevel mixed-effects logistic regression (model 1) demonstrated the risk of occurring dissatisfaction among various characteristics, and the coefficients in multilevel mixedeffects linear regression with 95\% CLs (model 2) showed the extent to which participants' dissatisfaction was associated with various characteristics. The statistical results and figures were processed with STATA statistical software version 14.0 (StataCorp LP, College Station, TX, USA) and Excel 2016, respectively. A two-tailed $p$-value of $<0.05$ was considered statistically significant.

\section{Results}

\subsection{Descriptive Statistics}

Figure 2 indicates that a total of $9 \%$ and $7 \%$ of participants reported "very dissatisfied" and "somewhat dissatisfied" with local medical services, respectively, while $46 \%$ of participants had a "neutral (neither satisfied nor dissatisfied)" attitude toward local medical services. After aggregating groups based on "somewhat dissatisfied" and "very dissatisfied" replies, overall 16\% of rural participants and 19\% of urban participants reported dissatisfaction with local medical services, respectively, while $44 \%$ of rural participants and 50\% of urban participants had a "neutral" attitude toward local medical services, respectively.

Table 2 presents the summary statistics of basic variables in our sample. The mean age of participants in this study was 61.99 years old. More than $70 \%$ of participants were rural residents. With regard to education level, illiterate participants accounted for $27.58 \%$ in rural and $9.33 \%$ in urban. Rural and urban participants living with others constitute the greatest proportion in the sample (78.04\% in rural and $79.18 \%$ in urban). The rates of having chronic diseases in the sample were $43.67 \%$ and $46.67 \%$ for rural and urban participants, respectively. In addition, $16.42 \%$ of rural participants and $16.77 \%$ of urban participants had at least one outpatient visit in the past one month, respectively; $16.67 \%$ of rural participants and $17.91 \%$ of urban participants had at least one inpatient visit in the last year, respectively. Only $4.62 \%$ of rural participants and $2.76 \%$ of urban participants received paid family doctor services, respectively. 


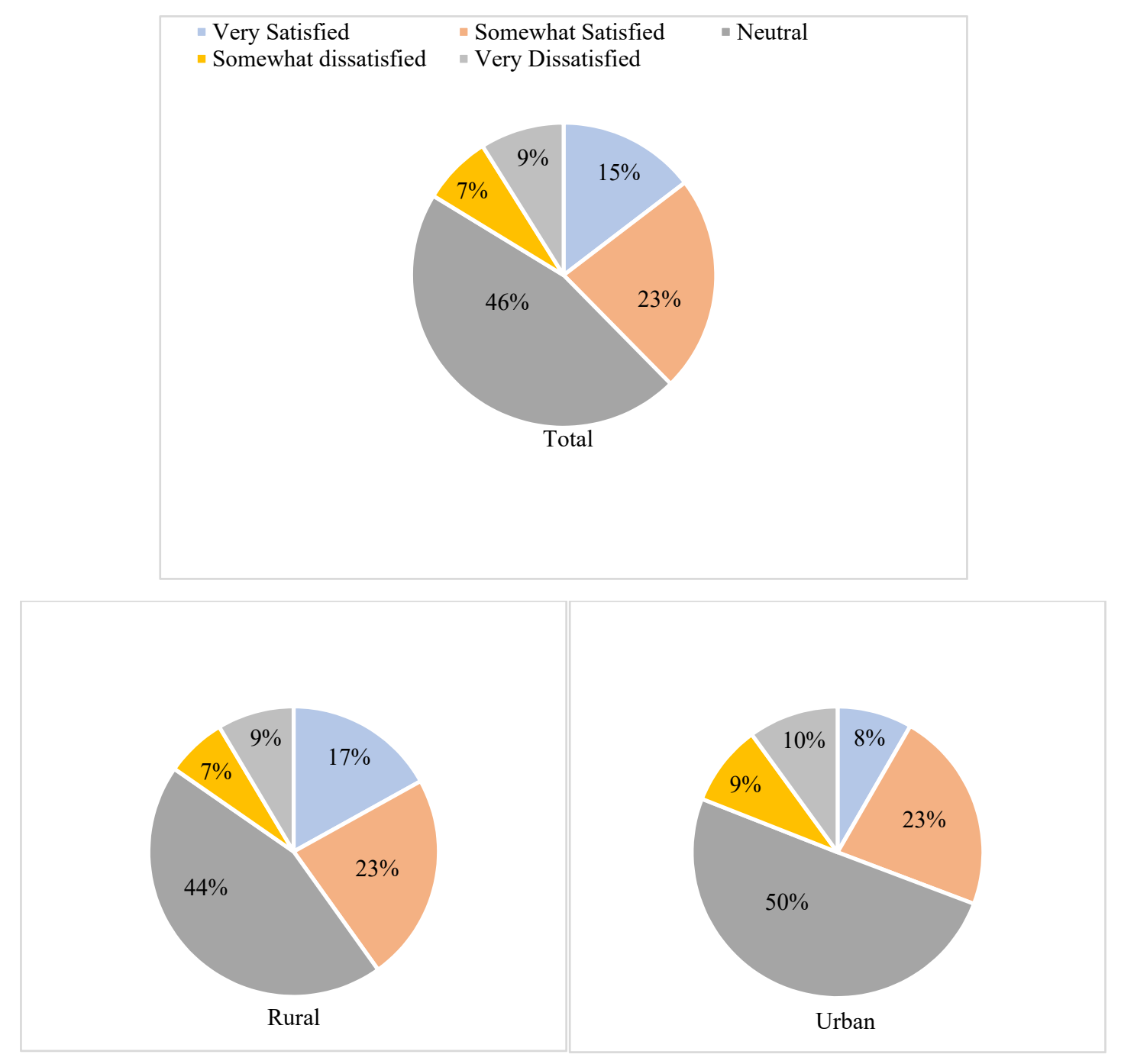

Figure 2. The distribution of participants' attitude to local medical services.

Table 3 shows the distribution of degree of dissatisfaction with local medical services: when dissatisfaction was treated as a continuous variable, the higher the score, and the more dissatisfied the participants. Overall, the mean score of dissatisfaction was $2.73 \pm 1.08$. Both urban and rural participants utilizing outpatients in the past month expressed higher dissatisfaction with local medical services than not utilized participants, while participants utilizing paid family doctor services showed less significantly $(p<0.05)$; male and participants having chronic diseases expressed more dissatisfaction $(p<0.001)$; in addition, the score of dissatisfaction increased with the decreasing of age and increasing of education level $(p<0.001)$. Table 4 also provides a comparison between dissatisfied and non-dissatisfied participants. Some characteristics of dissatisfied and non-dissatisfied groups for both rural and urban showed statistically significant differences. Participants were generally more dissatisfied with local medical services when they did not utilize paid family doctor services (rural: $15.63 \%$ vs. $10.14 \%, p<0.001$; urban: $19.29 \%$ vs. $9.92 \%$, $p=0.007$ ). Males appeared to be more dissatisfied with medical services than females (rural: $17.22 \%$ vs. $13.70 \%, p<0.001$; urban: $20.48 \%$ vs. $17.74 \%, p=0.017$ ). This is not surprising given that participants having chronic diseases have a higher degree of dissatisfaction (rural: $17.48 \%$ vs. $13.73 \%, p<0.001$; urban: $20.98 \%$ vs. $17.29 \%, p=0.001$ ). Moreover, urban participants utilizing more outpatient in the past one month and inpatient services in the last year tended to be more dissatisfied with local medical services (outpatient: $23.30 \%$ vs. 
$18.13 \%, p=0.001$; inpatient: $22.66 \%$ vs. $18.21 \%, p=0.003$ ), while there was no significant association among rural participants $(p>0.05)$.

Table 2. Description of characteristics $(n=19,161)$.

\begin{tabular}{|c|c|c|c|c|c|}
\hline \multirow{2}{*}{ Variables } & \multicolumn{2}{|c|}{ Rural $(n=14,263)$} & \multicolumn{2}{|c|}{ Urban $(n=4898)$} & \multirow{2}{*}{ Total } \\
\hline & Frequency & Percent & Frequency & Percent & \\
\hline \multicolumn{6}{|l|}{ Sex } \\
\hline Male & 6772 & 47.48 & 2326 & 47.49 & 9098 \\
\hline Female & 7491 & 52.52 & 2572 & 52.51 & 10,063 \\
\hline \multicolumn{6}{|l|}{ Age (years) } \\
\hline $45-50$ & 1749 & 12.26 & 679 & 13.86 & 2428 \\
\hline $51-60$ & 4596 & 32.22 & 1716 & 35.03 & 6312 \\
\hline $61-70$ & 4752 & 33.32 & 1513 & 30.89 & 6265 \\
\hline$\geq 71$ & 3166 & 22.20 & 990 & 20.22 & 4156 \\
\hline \multicolumn{6}{|l|}{ Education } \\
\hline Illiterate & 3934 & 27.58 & 457 & 9.33 & 4391 \\
\hline$\leq$ Elementary school & 6694 & 46.93 & 1524 & 31.11 & 8218 \\
\hline$\geq$ Middle school & 3635 & 25.49 & 2917 & 59.55 & 6552 \\
\hline \multicolumn{6}{|l|}{ Living status } \\
\hline Live with others & 11,131 & 78.04 & 3878 & 79.18 & 15,009 \\
\hline Live alone & 3132 & 21.96 & 1020 & 20.82 & 4152 \\
\hline \multicolumn{6}{|l|}{ Economic status } \\
\hline Low & 4143 & 29.05 & 444 & 9.06 & 4587 \\
\hline Middle & 7536 & 52.84 & 2089 & 42.65 & 9625 \\
\hline High & 2583 & 18.11 & 2365 & 48.29 & 4948 \\
\hline \multicolumn{6}{|l|}{ Chronic diseases } \\
\hline No & 8034 & 56.33 & 2612 & 53.33 & 10,646 \\
\hline Yes & 6229 & 43.67 & 2286 & 46.67 & 8515 \\
\hline \multicolumn{6}{|l|}{ Utilizing outpatients } \\
\hline No & 11,920 & 83.58 & 4075 & 83.23 & 15,995 \\
\hline Yes & 2342 & 16.42 & 821 & 16.77 & 3163 \\
\hline \multicolumn{6}{|l|}{ Utilizing inpatients } \\
\hline No & 11,885 & 83.33 & 4019 & 82.09 & 15,904 \\
\hline Yes & 2377 & 16.67 & 877 & 17.91 & 3254 \\
\hline \multicolumn{6}{|c|}{ Utilizing paid family doctor services } \\
\hline No & 13,603 & 95.38 & 4760 & 97.24 & 18,363 \\
\hline Yes & 659 & 4.62 & 135 & 2.76 & 794 \\
\hline
\end{tabular}

Table 3. Distribution of degree of dissatisfaction with local medical services.

\begin{tabular}{lcccccc}
\hline \multirow{2}{*}{ Variables } & \multicolumn{2}{c}{ Rural $(\boldsymbol{n = 1 4 , 2 6 3 )}$} & \multicolumn{3}{c}{ Urban $(\boldsymbol{n}=\mathbf{4 8 9 8})$} \\
\cline { 2 - 7 } & Mean \pm SD & t/F & $p$ & Mean \pm SD & t/F & $p$ \\
\hline Utilizing outpatients & & & & & & \\
$\quad$ No & $2.65 \pm 1.10$ & -3.42 & $<0.001$ & $2.88 \pm 1.00$ & -2.90 & 0.002 \\
$\quad$ Yes & $2.74 \pm 1.08$ & & & $2.99 \pm 1.08$ & & \\
\hline Utilizing inpatients & & & & & & \\
$\quad$ No & $2.67 \pm 1.09$ & 0.20 & 0.420 & $2.89 \pm 1.01$ & -1.77 & 0.039 \\
$\quad$ Yes & $2.67 \pm 1.13$ & & & $2.95 \pm 1.07$ & & \\
\hline
\end{tabular}


Table 3. Cont.

\begin{tabular}{|c|c|c|c|c|c|c|}
\hline \multirow{2}{*}{ Variables } & \multicolumn{3}{|c|}{ Rural $(n=14,263)$} & \multicolumn{3}{|c|}{ Urban $(n=4898)$} \\
\hline & Mean \pm SD & $t / F$ & $p$ & Mean \pm SD & $t / F$ & $p$ \\
\hline \multicolumn{7}{|c|}{ Utilizing paid family doctor services } \\
\hline No & $2.68 \pm 1.10$ & 6.79 & $<0.001$ & $2.91 \pm 1.02$ & 4.52 & $<0.001$ \\
\hline Yes & $2.38 \pm 1.04$ & & & $2.50 \pm 1.00$ & & \\
\hline \multicolumn{7}{|l|}{ Sex } \\
\hline Male & $2.74 \pm 1.11$ & 7.10 & $<0.001$ & $2.97 \pm 1.03$ & 4.14 & $<0.001$ \\
\hline Female & $2.60 \pm 1.09$ & & & $2.84 \pm 1.01$ & & \\
\hline \multicolumn{7}{|l|}{ Age (years) } \\
\hline $45-50$ & $2.80 \pm 0.99$ & 31.74 & $<0.001$ & $2.95 \pm 0.98$ & 3.31 & 0.019 \\
\hline $51-60$ & $2.75 \pm 1.07$ & & & $2.88 \pm 0.98$ & & \\
\hline $61-70$ & $2.62 \pm 1.13$ & & & $2.95 \pm 1.07$ & & \\
\hline$\geq 71$ & $2.55 \pm 1.13$ & & & $2.83 \pm 1.04$ & & \\
\hline \multicolumn{7}{|l|}{ Education } \\
\hline Illiterate & $2.49 \pm 1.16$ & 78.57 & $<0.001$ & $2.70 \pm 1.16$ & 14.70 & $<0.001$ \\
\hline$\leq$ Elementary school & $2.70 \pm 1.08$ & & & $2.85 \pm 1.06$ & & \\
\hline$\geq$ Middle school & $2.79 \pm 1.04$ & & & $2.96 \pm 0.97$ & & \\
\hline \multicolumn{7}{|l|}{ Living status } \\
\hline Live with others & $2.68 \pm 1.09$ & 1.62 & 0.053 & $2.91 \pm 1.00$ & 1.77 & 0.039 \\
\hline Live alone & $2.64 \pm 1.13$ & & & $2.85 \pm 1.10$ & & \\
\hline \multicolumn{7}{|l|}{ Economic status } \\
\hline Low & $2.68 \pm 1.15$ & 1.08 & 0.341 & $2.77 \pm 1.18$ & 3.98 & 0.019 \\
\hline Middle & $2.66 \pm 1.11$ & & & $2.93 \pm 1.04$ & & \\
\hline High & $2.68 \pm 1.00$ & & & $2.90 \pm 0.97$ & & \\
\hline \multicolumn{7}{|l|}{ Chronic diseases } \\
\hline No & $2.62 \pm 1.07$ & -5.73 & $<0.001$ & $2.84 \pm 1.01$ & -3.91 & $<0.001$ \\
\hline Yes & $2.73 \pm 1.13$ & & & $2.96 \pm 1.02$ & & \\
\hline
\end{tabular}

Table 4. Distribution of rate of dissatisfaction with local medical services.

\begin{tabular}{|c|c|c|c|c|c|c|}
\hline \multirow{2}{*}{ Variables } & \multicolumn{3}{|c|}{ Rural $(n=14,263)$} & \multicolumn{3}{|c|}{ Urban $(n=4898)$} \\
\hline & No & Yes & $p$ & No & Yes & $p$ \\
\hline \multicolumn{7}{|c|}{ Utilizing outpatients } \\
\hline No & $9711(84.83)$ & $1736(15.17)$ & 0.130 & $3165(81.87)$ & $701(18.13)$ & 0.001 \\
\hline Yes & $1925(83.59)$ & $378(16.41)$ & & $622(76.70)$ & $189(23.30)$ & \\
\hline \multicolumn{7}{|c|}{ Utilizing inpatients } \\
\hline No & $9700(84.83)$ & $1734(15.17)$ & 0.131 & $3118(81.79)$ & $694(18.21)$ & 0.003 \\
\hline Yes & $1936(83.59)$ & $380(16.41)$ & & $669(77.34)$ & $196(22.66)$ & \\
\hline \multicolumn{7}{|c|}{ Utilizing paid family doctor services } \\
\hline No & $11,051(84.37)$ & $2048(15.63)$ & $<0.001$ & $3669(80.71)$ & $877(19.29)$ & 0.007 \\
\hline Yes & $585(89.86)$ & $66(10.14)$ & & $118(90.08)$ & $13(9.92)$ & \\
\hline \multicolumn{7}{|l|}{ Sex } \\
\hline Male & $5413(82.78)$ & $1126(17.22)$ & $<0.001$ & $1751(79.52)$ & $451(20.48)$ & 0.017 \\
\hline Female & $6223(86.30)$ & $988(13.70)$ & & $2036(82.26)$ & 439 (17.74) & \\
\hline \multicolumn{7}{|l|}{ Age (years) } \\
\hline 45-50 & $1461(85.64)$ & 245 (14.36) & 0.224 & 519 (81.09) & $121(18.91)$ & 0.007 \\
\hline $51-60$ & 3739 (84.02) & 711 (15.98) & & $1370(83.03)$ & $280(16.97)$ & \\
\hline $61-70$ & $3882(84.32)$ & 722 (15.68) & & 1135 (78.17) & $317(21.83)$ & \\
\hline$\geq 71$ & $2554(85.42)$ & $436(14.58)$ & & $763(81.60)$ & $172(18.40)$ & \\
\hline
\end{tabular}


Table 4. Cont.

\begin{tabular}{|c|c|c|c|c|c|c|}
\hline \multirow{2}{*}{ Variables } & \multicolumn{3}{|c|}{ Rural $(n=14,263)$} & \multicolumn{3}{|c|}{ Urban $(n=4898)$} \\
\hline & No & Yes & $p$ & No & Yes & $p$ \\
\hline \multicolumn{7}{|l|}{ Education } \\
\hline Illiterate & $3231(86.30)$ & $513(13.70)$ & 0.001 & $351(82.78)$ & $73(17.22)$ & 0.568 \\
\hline$\leq$ Elementary school & $5477(84.50)$ & $1005(15.50)$ & & $1180(81.10)$ & $275(18.90)$ & \\
\hline$\geq$ Middle school & $2928(83.09)$ & $596(16.91)$ & & $2256(80.63)$ & $542(19.37)$ & \\
\hline \multicolumn{7}{|l|}{ Living status } \\
\hline Live with others & $9143(84.62)$ & $1662(15.38)$ & 0.964 & $3038(81.36)$ & $696(18.64)$ & 0.177 \\
\hline Live alone & $2493(84.65)$ & $452(15.35)$ & & 749 (79.43) & $194(20.57)$ & \\
\hline \multicolumn{7}{|l|}{ Economic status } \\
\hline Low & 3305 (83.06) & $674(16.91)$ & 0.001 & 337 (81.20) & $78(18.80)$ & 0.391 \\
\hline Middle & $6168(84.85)$ & $1101(15.15)$ & & $1591(80.07)$ & $396(19.93)$ & \\
\hline High & $2162(86.45)$ & $339(13.55)$ & & $1859(81.71)$ & $416(18.29)$ & \\
\hline \multicolumn{7}{|l|}{ Chronic diseases } \\
\hline No & $6655(86.27)$ & 1059 (13.73) & $<0.001$ & $2047(82.71)$ & $428(17.29)$ & 0.001 \\
\hline Yes & $4981(82.52)$ & 1055 (17.48) & & $1740(79.02)$ & $462(20.98)$ & \\
\hline
\end{tabular}

\subsection{Regression Results}

Table 5 presents the results of multilevel mixed-effect models (model 1 for binary outcome of dissatisfaction and model 2 for continuous outcome of dissatisfaction). In rural, model 1 showed the participants' utilization of paid family doctor services decreased the risk of occurring dissatisfaction (OR: 0.58, 95\% CL: 0.45, 0.76); compared with males, the risk of occurring dissatisfaction decreased by 25\% for females (OR: 0.75, 95\% CL: 0.67, $0.83)$; the risk of occurring dissatisfaction decreased with the increasing of economic status, and the risk decreased by $16 \%$ for participants having middle economic status (OR: $0.84,95 \%$ CL: $0.75,0.94$ ) and $27 \%$ for participants having high economic status (OR: $0.73,95 \%$ CL: $0.63,0.85)$, respectively; however, the risk of dissatisfaction was nearly 1.5 times for participants having chronic diseases compared with not having chronic diseases (OR: 1.33, 95\% CL: 1.20, 1.46). Unlike significant reasons for dissatisfaction found in model 1, model 2 found more reasons and retained the same tendency. The utilization of outpatient in the past month, education of more than elementary school and having chronic diseases were positively associated with the increasing dissatisfaction score $(p<0.05)$, while utilization of paid family doctor services, aged more than 51 years old and higher economic status were negatively associated with the increasing dissatisfaction score $(p<0.05)$.

In urban, model 1 found that the utilization of outpatient services (OR: 1.41,95\% CL: $1.17,1.72$ ), inpatient services (OR: 1.21, 95\% CL: 1.00, 1.47) and having chronic diseases (OR: $1.23,95 \%$ CL: $1.06,1.44)$ increased the risk of dissatisfaction significantly; meanwhile, being female (OR: 0.80, 95\% CL: 0.68, 0.93) and utilizing the paid family doctor services (OR: 0.46, 95\% CL: 0.25, 0.84) decreased the risk of dissatisfaction. Model 2 also indicates that the rate of dissatisfaction gradually increased with utilization of outpatient services, more than middle school education and having chronic diseases, while utilizing paid family doctor services, being female and aged more than 71 years were shown to be protective factors to dissatisfaction $(p<0.05)$. 
Table 5. Determinants of dissatisfaction with local medical services by multilevel mixed-effect models.

\begin{tabular}{|c|c|c|c|c|c|c|c|c|c|c|c|c|}
\hline \multirow{3}{*}{ Variables } & \multicolumn{6}{|c|}{ Rural } & \multicolumn{6}{|c|}{ Urban } \\
\hline & \multicolumn{3}{|c|}{ Model 1} & \multicolumn{3}{|c|}{ Model 2} & \multicolumn{3}{|c|}{ Model 1} & \multicolumn{3}{|c|}{ Model 2} \\
\hline & OR & $95 \% \mathrm{CL}$ & $p$ & $\beta$ & $95 \% \mathrm{CL}$ & $p$ & OR & $95 \% \mathrm{CL}$ & $p$ & $\beta$ & $95 \% \mathrm{CL}$ & $p$ \\
\hline Utilizing outpatients & 1.06 & $0.93,1.21$ & 0.357 & 0.07 & $0.02,0.12$ & 0.008 & 1.41 & $1.17,1.72$ & $<0.001$ & 0.12 & $0.04,0.20$ & 0.002 \\
\hline Utilizing inpatients & 1.02 & $0.90,1.16$ & 0.775 & -0.003 & $-0.05,0.05$ & 0.910 & 1.21 & $1.00,1.47$ & 0.056 & 0.04 & $-0.04,0.11$ & 0.323 \\
\hline \multicolumn{13}{|c|}{ Utilizing paid family doctor services } \\
\hline & 0.58 & $0.45,0.76$ & $<0.001$ & -0.31 & $-0.39,-0.22$ & $<0.001$ & 0.46 & $0.25,0.84$ & 0.011 & -0.39 & $-0.57,-0.22$ & $<0.001$ \\
\hline Female & 0.75 & $0.67,0.83$ & $<0.001$ & -0.11 & $-0.15,-0.07$ & $<0.001$ & 0.80 & $0.68,0.93$ & 0.004 & -0.11 & $-0.17,-0.06$ & $<0.001$ \\
\hline Age (51-60 years) & 1.07 & $0.91,1.26$ & 0.417 & -0.07 & $-0.13,-0.01$ & 0.017 & 0.85 & $0.67,1.10$ & 0.225 & -0.07 & $-0.16,0.02$ & 0.120 \\
\hline Age (61-70 years) & 1.05 & $0.89,1.24$ & 0.576 & -0.18 & $-0.24,-0.12$ & $<0.001$ & 1.14 & $0.87,1.46$ & 0.311 & -0.03 & $-0.12,0.07$ & 0.602 \\
\hline Age ( $\geq 71$ years) & 0.95 & $0.79,1.14$ & 0.580 & -0.24 & $-0.31,-0.17$ & $<0.001$ & 0.89 & $0.67,1.18$ & 0.410 & -0.11 & $-0.22,-0.01$ & 0.035 \\
\hline SElementary school & 1.07 & $0.94,1.22$ & 0.282 & 0.13 & $0.08,0.18$ & $<0.001$ & 1.08 & $0.79,1.46$ & 0.625 & 0.10 & $-0.01,0.22$ & 0.064 \\
\hline$\geq$ Middle school & 1.18 & $1.01,1.38$ & 0.036 & 0.19 & $0.13,0.25$ & $<0.001$ & 1.17 & $0.86,1.59$ & 0.304 & 0.20 & $0.09,0.32$ & $<0.001$ \\
\hline $\begin{array}{l}\text { Live alone } \\
\text { Lath }\end{array}$ & 1.04 & $0.92,1.17$ & 0.526 & 0.02 & $-0.03,0.06$ & 0.443 & 1.19 & $0.98,1.44$ & 0.083 & -0.03 & $-0.10,0.05$ & 0.492 \\
\hline Middle economic status & 0.84 & $0.75,0.94$ & 0.003 & -0.06 & $-0.10,-0.01$ & 0.008 & 0.99 & $0.75,1.33$ & 0.927 & 0.08 & $-0.02,0.19$ & 0.120 \\
\hline High economic status & 0.73 & $0.63,0.85$ & $<0.001$ & -0.09 & $-0.14,-0.03$ & 0.004 & 0.86 & $0.64,1.15$ & 0.298 & 0.01 & $-0.10,0.12$ & 0.878 \\
\hline Chronic diseases & 1.33 & $1.20,1.46$ & $<0.001$ & 0.12 & $0.09,0.16$ & $<0.001$ & 1.23 & $1.06,1.44$ & 0.009 & 0.12 & $0.06,0.18$ & $<0.001$ \\
\hline
\end{tabular}

Model 1: binary outcome of dissatisfaction; Model 2: continuous outcome of dissatisfaction; OR: odds ratios; CL: confidence limits; $\beta$ : coefficient.

\section{Discussion}

A quantitative exploration of the current status and causes of dissatisfaction with local medical services will not only enable medical institutions to identify problems and improve their services in a targeted manner but also enhance patients' trust and reliance on local healthcare, thus further facilitating timely access to care and promoting health for all [33]. Firstly, this study revealed the level of dissatisfaction of middle-aged and elderly with local medical services. Then, it investigated the specific reasons for dissatisfaction from the individual's perspective and identified areas for improvement. Overall, 16\% of middle-aged and elderly in China were dissatisfied with the local medical services, $38 \%$ of them were satisfied with the local medical services, $16 \%$ of rural participants and $19 \%$ of urban participants were dissatisfied with the services they received, respectively. This dissatisfaction was higher than an investigation conducted 10 years before in China (13\%) [10] but lower than those of studies conducted in Heilongjiang Province of China [9]; it was higher than those of studies conducted in the public and private wing of the health services in Ethiopia [13], in Dutch university medical centers [34] and in other developed countries [1] but lower than those of studies conducted in Tanzania [35], among psychiatric outpatients in Singapore [36] and diabetes mellitus patients in Pakistan [16]. This discrepancy among different studies in China may be due to the differences in the study population. In the current study, the study population was the middle-aged and elderly, which might have reduced their patient satisfaction as reported by other studies that as age increased patient satisfaction decreased [13,32]. Therefore, attention to improving the medical experience of the middle-aged and elderly is important in reducing dissatisfaction with the local medical services. The distinction in the level of satisfaction among different countries may be due to a gap in health systems [37]. More research is needed to verify the conclusion.

Previous studies showed that medical services (such as doctor and nurses services, medical equipment, waiting time) had significant impacts on dissatisfaction [15,38-40]. In the analysis, our results find that participants' utilization of outpatient, inpatient and paid family doctor services was one reason for dissatisfaction. Utilization of outpatient and inpatient services would increase the risk of occurring dissatisfaction. It is not difficult to understand that the more patients may utilize outpatient and inpatient services, the more likely they are to be dissatisfied due to the current status of crowded medical services and the attitude of the tired doctors they visit [41]. However, utilization of the paid family doctor services would decrease the risk of dissatisfaction. This is because research has shown that family doctors act as a bridge between patients and doctors, taking full account of the patient's feelings, promoting the patient's best interests in health care and helping the patient understand the outcome of the doctor's visit to the maximum extent possible. Ultimately, this promotes a good patient experience [42]. Therefore, the promotion of family doctor services can effectively reduce patients' dissatisfaction with the local medical services. 
With regard to the individual-level characteristics, our results show that dissatisfaction was more focused on males. Females were usually less dissatisfied, and this was in line with other studies indicating that being female was related to a lower rate of being dissatisfied $[10,13,16]$. The study also revealed that age was negatively associated with the increase of dissatisfaction. This finding is consistent with that of a study conducted in the public hospitals of Ethiopia: patients who were aged 38-47 years were more satisfied than those 48 years old and older groups [13]. This higher dissatisfaction may be related to the rising expectations of patients with increasing age; it may also be related to the fact that increasing knowledge and experience reduces satisfaction. In this study, the population that attended more than elementary school was positively associated with the increasing dissatisfaction score, and this finding is consistent with studies that revealed that as educational status increased, patient satisfaction decreased [13]. In addition, having chronic diseases were found to be positively associated with the increase of the dissatisfaction score. From this finding, it can be inferred that improving health status might improve patient satisfaction.

\section{Limitations}

Our understanding of dissatisfaction with local medical services is limited by some factors. Firstly, the study was not supported by qualitative methods. Secondly, the determinants of dissatisfaction were limited by the pre-specified questions in the survey, and there could be some potential unobserved confounding factors for which we did not control. For instance, distance to hospital and attitude of the doctor. Thirdly, this study is a correlation analysis, and the results should not be interpreted as causal. However, we believe that the results measured by this nationally representative sample will provide useful insights into improving the quality and efficiency of local medical services in China.

\section{Conclusions}

This pooled analysis of 14,263 rural and 4898 urban populations suggests that dissatisfaction with the local medical services was more focused on males, participants not utilizing the paid family doctor services and participants with chronic diseases. Therefore, promotion of family doctor services can effectively reduce patients' dissatisfaction with the local medical services. In addition, more attention should be focused on males and participants with chronic diseases in order to decrease dissatisfaction with the local medical services. Studying the factors behind patients' dissatisfaction with the local medical services is important for the provision of services as per patient needs; it helps hospital managers to improve the service experience and quality in a targeted manner based on the reasons. However, the findings of this study can only suggest an association between these reasons and patients' dissatisfaction and cannot be interpreted as causal; more evidence based on a combination of quantitative studies (e.g., experimental study) and qualitative studies is needed to validate the causality in the next research steps.

Author Contributions: Conceptualization, X.F., M.S. and D.W.; formal analysis, X.F., Y.Z. and M.S.; writing-original draft preparation, X.F., M.S. and Y.Z.; writing—review and editing, X.F., M.S. and D.W.; supervision, M.S. and D.W.; funding acquisition, X.F. and M.S. All authors have read and agreed to the published version of the manuscript.

Funding: This research was funded by the National Natural Science Foundation of China (grant number: 72004178) and Natural Science Foundation of Inner Mongolia (grant number: 2020BS07002). The APC was funded by the Natural Science Foundation of Inner Mongolia, grant number 2020BS07002.

Institutional Review Board Statement: The study was conducted according to the guidelines of the Declaration of Helsinki and approved by the Institutional Review Board of Peking University (protocol code IRB00001052-11015 and January 2011). Ethics approval for the study was granted by the Ethics Review Committee of Peking University.

Informed Consent Statement: Informed consent was obtained from all subjects involved in the study. 
Data Availability Statement: The datasets and questionnaire are available at http:/ / charls.pku.edu. cn/ (accessed on 23 September 2020).

Acknowledgments: We thank the China Health and Retirement Longitudinal Study (CHARLS) team for providing data. We would also like to express our appreciation to all participants in our study for their participation and cooperation.

Conflicts of Interest: The authors declare no conflict of interest. The funders had no role in the design of the study; in the collection, analyses, or interpretation of data; in the writing of the manuscript, or in the decision to publish the results.

\section{References}

1. Bleich, S.N.; Ozaltin, E.; Murray, C.J.L. How does satisfaction with the health-care system relate to patient experience? B World Health Organ. 2009, 87, 271-278. [CrossRef]

2. Ruggieri, T.G.; Berta, P.; Murante, A.M.; Nuti, S. Patient satisfaction, patients leaving hospital against medical advice and mortality in Italian university hospitals: A cross-sectional analysis. BMC Health Serv. Res. 2018, 18, 51. [CrossRef]

3. Gunaratne, R.; Pratt, D.N.; Banda, J.; Fick, D.P.; Khan, R.J.; Robertson, B.W. Patient Dissatisfaction Following Total Knee Arthroplasty: A Systematic Review of the Literature. J. Arthroplast. 2017, 32, 3854-3860. [CrossRef] [PubMed]

4. Coulter, A. Can patients assess the quality of health care? Patients' surveys should ask about real experiences of medical care. Brit. Med. J. 2006, 333, 1-2. [CrossRef] [PubMed]

5. Jameel, A.; Asif, M.; Hussain, A.; Hwang, J.; Bukhari, M.H.; Mubeen, S.; Kim, I. Improving Patient behavioral Consent through Different Service Quality Dimensions: Assessing the Mediating Role of Patient Satisfaction. Int. J. Environ. Res. Public Health 2019, 16, 4736. [CrossRef] [PubMed]

6. Mao, Y.; Xie, T.; Ning, W. The influence of medical service quality on patients' perception of doctor-patient relationship: Mediating effect analysis based on patient satisfaction. J. Xi'an Jiaotong Univ. (Soc. Sci.) 2020, 40, 119-127.

7. Sun, J.; Zhang, L.; Yu, Y.; Ma, N.; He, C. Interpretation of the behavioral economics and countermeasures of the risk in doctor-patient relationship. Acta Univ. Med. Nanjing (Soc. Sci.) 2016, 16, 141-145.

8. Perneger, T.V.; Peytremann-Bridevaux, I.; Combescure, C. Patient satisfaction and survey response in 717 hospital surveys in Switzerland: A cross-sectional study. BMC Health Serv. Res. 2020, 20, 158. [CrossRef]

9. Shan, L.; Li, Y.; Ding, D.; Wu, Q.; Liu, C.; Jiao, M.; Hao, Y.; Han, Y.; Gao, L.; Hao, J.; et al. Patient Satisfaction with Hospital Inpatient Care: Effects of Trust, Medical Insurance and Perceived Quality of Care. PLoS ONE 2016, 11, e0164366. [CrossRef]

10. Pan, J.; Liu, D.; Ali, S. Patient dissatisfaction in China: What Matters. Soc. Sci. Med. 2015, 143, 145-153. [CrossRef]

11. Stevens, L.M. "We have to be mythbusters": Clinician attitudes about the legitimacy of patient concerns and dissatisfaction with contraception. Soc. Sci. Med. 2018, 212, 145-152. [CrossRef]

12. Minnick, A.F.; Roberts, M.J.; Young, W.B.; Kleinpell, R.M.; Marcantonio, R.J. What influences patients' reports of three aspects of hospital services? Med. Care 1997, 35, 399-409. [CrossRef]

13. Geberu, D.M.; Biks, G.A.; Gebremedhin, T.; Mekonnen, T.H. Factors of patient satisfaction in adult outpatient departments of private wing and regular services in public hospitals of Addis Ababa, Ethiopia: A comparative cross-sectional study. BMC Health Serv. Res. 2019, 19, 1-13. [CrossRef]

14. Cohen, G. Age and health status in a patient satisfaction survey. Soc. Sci. Med. 1996, 42, 1085-1093. [CrossRef]

15. Aziz, M.M.; Ji, W.; Masood, I.; Farooq, M.; Malik, M.Z.; Chang, J.; Jiang, M.; Atif, N.; Fang, Y. Patient Satisfaction with Community Pharmacies Services: A Cross-Sectional Survey from Punjab; Pakistan. Int. J. Environ. Res. Public Health 2018, 15, 2914. [CrossRef] [PubMed]

16. Jalil, A.; Zakar, R.; Zakar, M.Z.; Fischer, F. Patient satisfaction with doctor-patient interactions: A mixed methods study among diabetes mellitus patients in Pakistan. BMC Health Serv. Res. 2017, 17, 1-13. [CrossRef]

17. Wu, D.; Huang, X.; Hu, C.; Yan, S.; Zhang, Y. Satisfaction influencing factors of family doctors' contracted services among contracted patients with chronic diseases. J. Nanjing Med. Univ. (Soc. Sci.) 2020, 20, 71-76.

18. Yang, Y.; Zhu, Z.; Jiang, Y.; Yu, J.; Luan, W.; Shi, W. Analysis of the effectiveness of in and out hospital services and patient satisfaction in a tertiary public hospital. Chin. Hosp. Manag. 2021, 41, 63-66.

19. Key Data Release of the Sixth National Population Census. Available online: http://www.stats.gov.cn/ztjc/zdtjgz/zgrkpc/ dlcrkpc/dcrkpcyw/201104/t20110428_69407.htm (accessed on 28 April 2011).

20. Corder, L.S.; Woodbury, M.A.; Manton, K.G. Proxy response patterns among the aged: Effects on estimates of health status and medical care utilization from the 1982-1984 long-term care surveys. J. Clin. Epidemiol. 1996, 49, 173-182. [CrossRef]

21. McFadden, E.; Luben, R.; Bingham, S.; Wareham, N.; Kinmonth, A.-L.; Khaw, K.-T. Social inequalities in self-rated health by age: Cross-sectional study of 22457 middle-aged men and women. BMC Public Health 2008, 8, 230. [CrossRef]

22. Wu, F.; Guo, Y.; Kowal, P.; Jiang, Y.; Yu, M.; Li, X.; Zheng, Y.; Xu, J. Prevalence of Major Chronic Conditions among Older Chinese Adults: The Study on Global AGEing and Adult Health (SAGE) Wave 1. PLoS ONE 2013, 8, e74176. [CrossRef]

23. Wang, R.; Yan, Z.; Liang, Y.; Tan, E.C.K.; Cai, C.; Jiang, H.; Song, A.; Qiu, C. Prevalence and Patterns of Chronic Disease Pairs and Multimorbidity among Older Chinese Adults Living in a Rural Area. PLoS ONE 2015, 10, e0138521. [CrossRef] 
24. Hu, B.; Peng, D.Y.; Zhang, Y.D.; Yu, J.Y. Rural population aging and the hospital utilization in cties: The rise of medical tourism in China. Int. J. Environ. Res. Public Health 2020, 17, 4790. [CrossRef]

25. Zhao, Y.; Hu, Y.; Smith, J.P.; Strauss, J.; Yang, G. Cohort Profile: The China Health and Retirement Longitudinal Study (CHARLS). Int. J. Epidemiol. 2014, 43, 61-68. [CrossRef] [PubMed]

26. Ma, X.; Oshio, T. The impact of social insurance on health among middle-aged and older adults in rural China: A longitudinal study using a three-wave nationwide survey. BMC Public Health 2020, 20, 1842.

27. Zhao, Y.; Strauss, J.; Yang, G.; Giles, J.; Hu, P.P.; Hu, Y.; Lei, X.; Park, A.; Smith, J.P.; Wang, Y. China Health and Retirement Longitudinal Study, 2011-2012 National Baseline Users' Guide; Peking University: Beijing, China, 2013; p. 8.

28. Crow, R.; Gage, H.; Hampson, S.; Hart, J.; Kimber, A.; Storey, L.; Thomas, H. The measurement of satisfaction with healthcare: Implications for practice from a systematic review of the literature. Health Technol. Assess. 2002, 6, 1-244. [CrossRef]

29. Strasser, S.; Aharony, L.; Greenberger, D. The Patient Satisfaction Process: Moving Toward a Comprehensive Model. Med Care Rev. 1993, 50, 219-248. [CrossRef]

30. Ware, J.E.; Snyder, M.K.; Wright, W.; Davies, A.R. Defining and measuring patient satisfaction with medical care. Eval. Program Plan. 1983, 6, 247-263. [CrossRef]

31. Wang, J.; Okoli, C.T.; He, H.; Feng, F.; Li, J.; Zhuang, L.; Lin, M. Factors associated with compassion satisfaction, burnout, and secondary traumatic stress among Chinese nurses in tertiary hospitals: A cross-sectional study. Int. J. Nurs. Stud. 2020, 102, 103472. [CrossRef]

32. DeVoe, J.E.; Wallace, L.S.; Fryer, G.E. Patient age influences perceptions about health care communication. Fam. Med. 2009, 41, $126-133$.

33. Javed, S.A.; Liu, S.; Mahmoudi, A.; Nawaz, M. Patients' satisfaction and public and private sectors' health care service quality in Pakistan: Application of grey decision analysis approaches. Int. J. Health Plan. Manag. 2019, 34, e168-e182. [CrossRef]

34. Kleefstra, S.M.; Zandbelt, L.C.; De Haes, H.J.C.J.M.; Kool, R.B. Trends in patient satisfaction in Dutch university medical centers: Room for improvement for all. BMC Health Serv. Res. 2015, 15, 112. [CrossRef]

35. Mfinanga, S.G.; Kahwa, A.; Kimaro, G.; Kilale, A.; Kivuyo, S.; Senkoro, M.; Ngowi, B.; Mtandu, R.; Mutayoba, B.; Ngadaya, E.; et al. Patient's dissatisfaction with the public and private laboratory services in conducting HIV related testing in Tanzania. BMC Health Serv. Res. 2008, 8, 167. [CrossRef]

36. Satghare, P.; Mahesh, M.V.; Abdin, E.; Chong, S.A.; Subramaniam, M. The Relative Associations of Body Image Dissatisfaction among Psychiatric Out-Patients in Singapore. Int. J. Environ. Res. Public Health 2019, 16, 5162. [CrossRef]

37. Popa, D.; Drugus, D.; Leașu, F.; Azoicăi, D.; Repanovici, A.; Rogozea, L.M. Patients' perceptions of healthcare professionalism-a Romanian experience. BMC Health Serv. Res. 2017, 17, 463. [CrossRef]

38. Hussain, A.; Asif, M.; Jameel, A.; Hwang, J. Measuring OPD Patient Satisfaction with Different Service Delivery Aspects at Public Hospitals in Pakistan. Int. J. Environ. Res. Public Health 2019, 16, 2340. [CrossRef] [PubMed]

39. Omer, K.; Cockcroft, A.; Andersson, N. Impact of a hospital improvement initiative in Bangladesh on patient experiences and satisfaction with services: Two cross-sectional studies. BMC Health Serv. Res. 2011, 11, S10. [CrossRef] [PubMed]

40. Hussain, A.; Asif, M.; Jameel, A.; Hwang, J.; Sahito, N.; Kanwel, S. Promoting OPD Patient Satisfaction through Different Healthcare Determinants: A Study of Public Sector Hospitals. Int. J. Environ. Res. Public Health 2019, 16, 3719. [CrossRef]

41. Liu, M.; Liu, W.; Tao, S.; Xue, Y.; Liang, L. Analysis of the patients' satisfaction of treatment links in public hospitals. Chin. Hosp. Manag. 2019, 39, 28-30.

42. Marcinowicz, L.; Chlabicz, S.; Grebowski, R. Patient satisfaction with healthcare provided by family doctors: Primary dimensions and an attempt at typology. BMC Health Serv. Res. 2009, 9, 63. [CrossRef] 